\title{
Predicting Geotechnical Investigation Using the Knowledge Based System
}

\author{
Bojan Žlender and Primož Jelušič \\ Faculty of Civil Engineering, Transportation Engineering and Architecture, University of Maribor, \\ Smetanova 17, SI-2000 Maribor, Slovenia
}

Correspondence should be addressed to Primož Jelušič; primoz.jelusic@um.sì

Received 16 November 2015; Accepted 17 March 2016

Academic Editor: Zeki Ayag

Copyright (C) 2016 B. Žlender and P. Jelušič. This is an open access article distributed under the Creative Commons Attribution License, which permits unrestricted use, distribution, and reproduction in any medium, provided the original work is properly cited.

\begin{abstract}
The purpose of this paper is to evaluate the optimal number of investigation points and each field test and laboratory test for a proper description of a building site. These optimal numbers are defined based on their minimum and maximum number and with the equivalent investigation ratio. The total increments of minimum and maximum number of investigation points for different building site conditions were determined. To facilitate the decision-making process for a number of investigation points, an Adaptive Network Fuzzy Inference System (ANFIS) was proposed. The obtained fuzzy inference system considers the influence of several entry parameters and computes the equivalent investigation ratio. The developed model (ANFIS-SI) can be applied to characterize any building site. The ANFIS-SI model takes into account project factors which are evaluated with a rating from 1 to 10. The model ANFIS-SI, with integrated recommendations can be used as a systematic decision support tool for engineers to evaluate the number of investigation points, field tests, and laboratory tests for a proper description of a building site. The determination of the optimal number of investigative points and the optimal number of each field test and laboratory test is presented on reference
\end{abstract} case.

\section{Introduction}

Planning geotechnical investigations is an important part of geotechnical design. The extent of the investigation should be based on the relationship between the surface conditions, subsurface conditions, and the project type. Insufficient geotechnical investigations can lead to inappropriate designs, delays in construction schedules, environmental damage to the site, costly construction modifications, and other problems.

There are many differences in opinion, among geotechnical experts from various countries, about the minimum quantity of tests that are required before a project can begin, that is, which and how many field and laboratory tests to carry out. In general, we know that if the quantity of investigations is too low, the risks become higher. Therefore, doing more investigations reduces the risks. However, when the risk is adequately low, more investigations will not significantly reduce the risks. For the remainder of this paper, this limit will be referred to as the optimum value of geotechnical investigation.

Determining the amount of preliminary site testing for a project depends on many factors, such as the type of structure, project area, structure geometry, the loading and sensitivity of the structure, site geology, the complexity of the geological structure, and similarities between the preliminary and general layout of the surrounding environment. The purpose of this paper is to evaluate the optimum value of geotechnical investigation needed before starting a project, as they depend on the above-mentioned factors. The optimum value of geotechnical investigation means the optimum number of investigation points, field tests, and laboratory tests that will give an adequate description of a building site.

The Eurocode 7-2 is a testing code that is used to adequately describe essential ground properties and make reliable assessments of ground parameters [1]. This code 
provides guidelines for carrying out preliminary geotechnical site testing and suggests the spacing scheme of individual ground samples and the minimum number of field tests and laboratory tests required before an engineering project can begin. Guidelines on the minimum number of individual ground samples are also available from other sources [2-4]. For example, Clayton et al. [5] have shown the impact that geologic, seismologic, and soil conditions can have on the design, safety, cost effectiveness, and execution of a proposed engineering project.

Research for this paper was carried out with the objective of unifying the criteria for geotechnical investigations and to develop a model for determining the optimum number of tests required before starting a project. The AdaptiveNetwork-Based Fuzzy Inference System (ANFIS) model was developed for this purpose. The basic structure of the fuzzy inference system (FIS) was introduced by Zadeh [6]. ANFIS, introduced by Jang [7], uses a given input/output data to construct a FIS, whose membership function parameters are adjusted using a backpropagation algorithm either alone or in combination with the Least Squares Method. This adjustment allows fuzzy systems to learn from the data they are modeling. ANFIS only supports Sugeno [8] identification models, which should only have one output parameter. The Adaptive Network is a superset of all kinds of feed-forward neural networks with supervised learning capability [9]. ANFIS is a fuzzy inference system implemented within the framework of adaptive networks and uses the advantages of neural networks and fuzzy logic.

Using the Nonstructural Fuzzy Decision Support System (NSFDSS) for site layout planning was proposed by Tam et al. [10]. This model integrates both experts' judgment and computer-based decision modeling, thus making it suitable for the appraisal of complicated construction problems. The model provides a systematic procedure for helping project managers or planning engineers in determining site facility allocations. Huang et al. [11] developed a servo-control algorithm that uses fuzzy logic for automated soil testing. This paper introduces the concept of fuzzy control and its application in soil testing. Basheer et al. [12] showed that neural networks can be used to map and logically predict the variation of soil permeability in order to identify landfill boundaries and construct waste landfills. Rizzo et al. [13] presented a new site characterization method called SCANN (Site Characterization using Artificial Neural Networks) that is based on the use of neural networks to map the discrete spatially distributed fields.

These examples demonstrate that the ANFIS model has a superior method for solving problems in which there are many complex parameters that have an impact on both the process and results. This is valid when the process and results are not fully described and where experimental data are available.

The prediction of the quantity of field and laboratory tests is also of this type. The use of the ANFIS-SI model is presented on the numerical example. It is presented in such a form that anyone can repeat it and use it for planning geotechnical investigations.

\section{Concept for Planning Geotechnical Investigation}

The preliminary investigations and project conditions are necessary to get the information about the project structure, type of foundation, depth of foundation, groundwater level, and ground layering. Based on these conditions and on personal experience with past projects, an engineer must decide how many geotechnical investigations will be sufficient for a given project.

2.1. Quantity of Investigation. The Eurocode 7 [1] gives recommendations for how many samples should be tested for each stratum and how many field tests and laboratory tests should be carried out for each stratum. The number of samples and tests that should be done for each stratum, adapted from Bond and Harris [14], depends on the level of comparable experience: either extensive, medium, or none (see Figure 1). For the comparable experience level titled extensive, the minimum number $\left(N_{T, i, \min }\right)$ of each type of test is needed; for the comparable experience level titled none (or nonextensive), the maximum number $\left(N_{T, i, \max }\right)$ of each type of test is needed.

The optimal number of field and laboratory tests for each stratum $\left(N_{T, i, l, \text { opt }}\right)$ is defined by the equivalent investigation ratio $\left(r_{\mathrm{EQ}}\right)$. The optimum number of investigations is found between the minimum number $\left(N_{T, i, l, \min }\right)$ of investigations and the maximum number $\left(N_{T, i, l, \max }\right)$ of investigations (see the following):

$$
\begin{aligned}
& N_{T, i, l, \text { min }} \leq N_{T, i, l, \text { opt }} \leq N_{T, i, l, \text { max }} \\
& N_{T, i, l, \text { opt }}=N_{T, i, l, \text { min }}+\left(N_{T, i, l, \text { max }}-N_{T, i, l, \text { min }}\right) \cdot r_{\mathrm{EQ}} .
\end{aligned}
$$

An engineer's judgment about the number of field and laboratory tests needed for a project is based on several impact parameters. When these parameters are favorable, the engineer has a relatively easy decision to make about the quantity of field and laboratory test $\left(r_{\mathrm{EQ}}=0\right)$. When the parameters are unfavorable, more field and laboratory tests should be done. And for extremely unfavorable conditions, the maximum number of field and laboratory tests are required $\left(r_{\mathrm{EQ}}=1\right)$ :

$$
0 \leq r_{\mathrm{EQ}} \leq 1
$$

The total value of the optimal number $\left(\operatorname{Sum} N_{T, i, o p t}\right)$ for each field and each laboratory test $(i)$ is defined as the sum of the optimal number for every stratum $l\left(N_{T, i, l, o p t}\right)$ :

$$
\operatorname{Sum} N_{T, i, \mathrm{opt}}=\sum_{l=1}^{\text {Nlay }} N_{T, i, l, \mathrm{opt}} .
$$

The minimum number of each field and laboratory test required for the comparable experience level extensive $\left(N_{T, i, \min }\right)$ can be expressed as the lower number of each test $\left(N_{T, i, \mathrm{EXL}}\right)$ and the upper number of each test $\left(N_{T, i, \mathrm{EXH}}\right)$, as a function of the project area $(A)$, the lower value of the project 

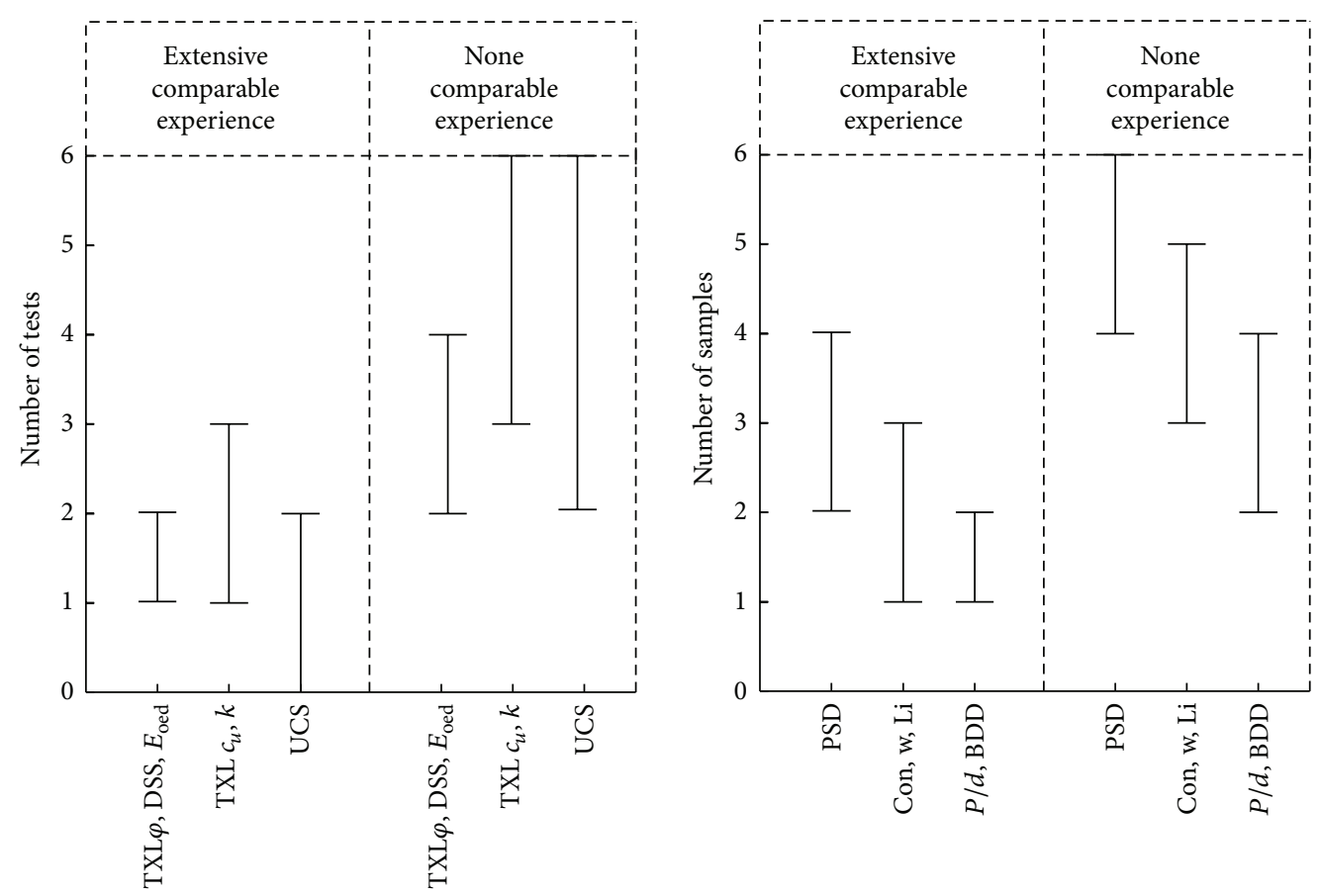

FIGURE 1: Number of samples and tests needed for each stratum. BDD: bulk density determination. DSS: direct shear tests. $E_{\text {oed }}$ : incremental oedometer tests and permeability. $k$ : permeability tests. UCS: unconfined compressive strength tests on rock. PSD: particle size distribution and permeability. Con: Consistency and Atterberg tests. w: water content. Li: loss on ignition. $P / d$ : particle density determination. TXL $\varphi$ : triaxial tests to determine the effective angel of shearing resistance. TXL $c_{u}$ : triaxial tests to determine the undrained shear strength.

area $\left(A_{L}\right)$, and the upper value of the project area $\left(A_{H}\right)$ (see (5), Figure 2):

$$
N_{T, i, \min }=N_{T, i, \mathrm{EXL}}+\left(N_{T, i, \mathrm{EXH}}-N_{T, i, \mathrm{EXL}}\right) \cdot \frac{A-A_{L}}{A_{H}-A_{L}} .
$$

The maximum number of each field and laboratory test is expressed for the noncomparable experience (see (6), Figure 2):

$$
N_{T, i, \max }=N_{T, i, \mathrm{NON}} .
$$

According to the Eurocode 7's recommendations, adapted from Bond and Harris [14] and (5)-(6), the lower number of each test $\left(N_{T, i, \mathrm{EXL}}\right)$ and the upper number of tests required $\left(N_{T, i, \mathrm{EXH}}\right)$ for the comparable experience level extensive and nonextensive $\left(N_{T, i, \mathrm{NON}}\right)$ should be done for each test.

Sampling tests should be performed on all boreholes. Sometimes it is also necessary to perform field tests on them. In view of this, it is necessary to first determine the number of investigation points that are required. For a proper description of the essential ground properties and a reliable assessment of ground parameters, an optimum number of investigation points $\left(N_{\mathrm{IP}, \text { opt }}\right)$ need to be defined. This number can also be defined by the equivalent investigation ratio $\left(r_{\mathrm{EQ}}\right)$ between the minimum and maximum number of investigation points:

$$
\begin{aligned}
N_{\mathrm{IP}, \text { min }} & \leq N_{\mathrm{IP}, \mathrm{opt}} \leq N_{\mathrm{IP}, \text { max }}, \\
N_{\mathrm{IP}, \mathrm{opt}} & =N_{\mathrm{IP}, \text { min }}+\left(N_{\mathrm{IP}, \text { max }}-N_{\mathrm{IP}, \text { min }}\right) \cdot r_{\mathrm{EQ}} .
\end{aligned}
$$

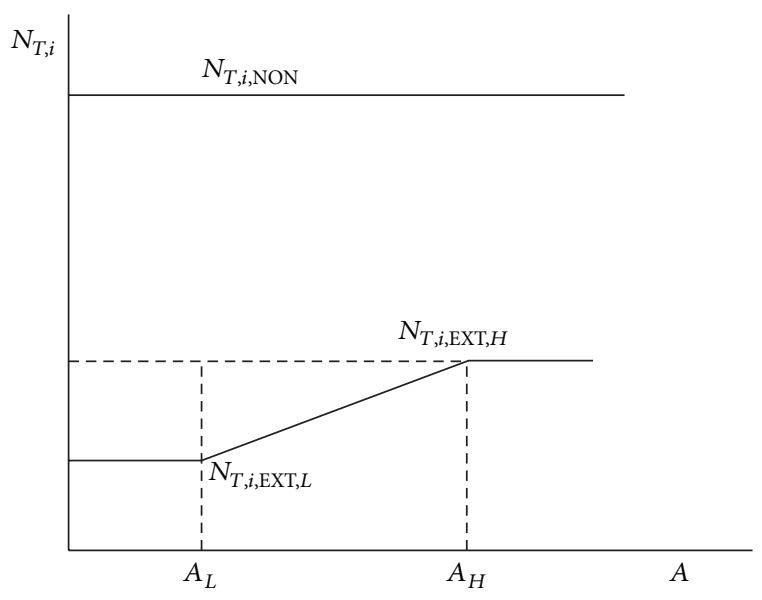

FIGURE 2: Number of samples and tests to be carried out for each stratum.

2.2. Project Factors. The quantity of investigations also depends on many other project factors. These factors are referred to as the ANFIS system input factors. Each input factor $(k)$ has a value between $r_{k}=1$ and $r_{k}=r_{k, \max }$. The equivalent investigation ratio $\left(r_{\mathrm{EQ}}\right)$ is expressed as a function of the project factors $\left(r_{k}\right)$.

From (2) and (6), written in general form it follows

$$
\begin{aligned}
N & =N_{\text {min }}+\left(N_{\max }-N_{\min }\right) \cdot r_{\mathrm{EQ}}, \\
N-N_{\min } & =\left(N_{\text {max }}-N_{\min }\right) \cdot r_{\mathrm{EQ}} .
\end{aligned}
$$


Value $N$ can be written in form

$$
N=\left(r_{1} \cdot r_{2} \cdot r_{k} \cdot r_{m}\right) \cdot N_{\min }
$$

When all factors have a minimum value $\left(r_{i, \min }=1\right)$ then

$$
N=\left(r_{1, \min } \cdot r_{2, \min } \cdot r_{k, \min } \cdot r_{m, \min }\right) \cdot N_{\min }=N_{\min }
$$

and maximum value $\left(r_{i, \max }\right)$ then

$$
N=\left(r_{1, \max } \cdot r_{2, \max } \cdot r_{k, \text { max }} \cdot r_{m, \max }\right) \cdot N_{\min }=N_{\max } \cdot
$$

It follows

$$
\begin{aligned}
& \frac{\left(r_{1} \cdot r_{2} \cdot r_{k} \cdot r_{m}\right) \cdot N_{\min }}{N_{\min }}-\frac{N_{\min }}{N_{\min }} \\
& =\left[\frac{\left(r_{1, \max } \cdot r_{2, \max } \cdot r_{k, \text { max }} \cdot r_{m, \max }\right) \cdot N_{\min }}{N_{\min }}-\frac{N_{\min }}{N_{\min }}\right] \\
& \text { - } r_{\mathrm{EQ}} \\
& r_{\mathrm{EQ}}=\frac{r_{1} \cdot r_{2} \cdot r_{k} \cdot r_{m}-1}{r_{1, \text { max }} \cdot r_{2, \text { max }} \cdot r_{k, \text { max }} \cdot r_{m, \text { max }}-1} .
\end{aligned}
$$

2.3. ANFIS Input Factors. Determining the correct number of investigations to perform depends on many factors. These factors include type of structure, project area, stratification, layout geometry, loading/sensitivity of structure, site geology, complexity of geological structure, variability of soil layers, and the similarity between preliminary and existing surrounding environment.

For this paper, a system of ANFIS input factors is presented; an evaluation of these factors is shown in [15]. Using this system, the equivalent investigation ratio $\left(r_{\mathrm{EQ}}\right)$ is expressed as a function of input factors (see (13)). However, the main difference from paper [15] is that this paper provides additionally the optimal number of laboratory and field tests and not only the number of investigation points.
2.4. Decision Criteria. The decision criteria (see, e.g., Table 3) should be as clear and detailed as possible so that anyone can set values from 1 to 10 for each parameter of the building site. It is also necessary to involve as many experts as possible. This will help in adapting the impact of the individual parameters to the number of investigation points.

\section{ANFIS Model for Building Site Investigations}

The ANFIS model was developed to predict the optimal number of field and laboratory tests required for a project. The ANFIS model has inputs and one output $r_{\mathrm{EQ}}$. An additional model, the ANFIS-SI, was developed in order to predict the optimal number of tests. The MATLAB [16] was used as an interface between mathematical modeling and data inputs/outputs. This is a system that uses a high-level technical computing language.

3.1. Data Set. One of the most important stages in the ANFIS technique is collecting the data. First, the space is determined (Figure 3). The space is composed of four parameters using intervals from 1 to 10 . Values with the factors of $r_{k}$ were determined for all the vertices. A system for determining the values of the vertices is presented in Table 1 .

The training dataset of building sites can also be improved. Parameter values and the optimum number of investigation points can be assigned to this dataset. In this model, $m$ evaluations are defined for various site conditions. In the most favorable situation, the values of all parameters are equal to 1 and the minimal number of equivalent investigation ratio $r_{\mathrm{EQ}}$ values is proposed as $r_{\mathrm{EQ}}=0$. Other vertices are obtained by considering the maximal ratios $\left(r_{1, \text { max }}, r_{2, \text { max }}, r_{k, \text { max }}, r_{m \text {, max }}\right)$ for each parameter.

3.2. ANFIS Structure. For the Sugeno fuzzy model, a rule set with $n$ fuzzy "If-then" is as follows:

Rule 1:

$$
\text { If } \mathrm{IP}_{1} \text { is } A_{1} \text { and } \mathrm{IP}_{2} \text { is } B_{1} \text { and } \mathrm{IP}_{k} \text { is } K_{1} \text { and } \mathrm{IP}_{m} \text { is } M_{1} \text { then } r_{\mathrm{EQ}, 1}=a^{1} \text {, }
$$

Rule $i$ :

$$
\text { If } \mathrm{IP}_{1} \text { is } A_{i} \text { and } \mathrm{IP}_{2} \text { is } B_{i} \text { and } \mathrm{IP}_{k} \text { is } K_{i} \text { and } \mathrm{IP}_{m} \text { is } M_{i} \text { then } r_{\mathrm{EQ}, i}=a^{i} \text {, }
$$

Rule $n$ : 
TABLE 1: Training datasets.

\begin{tabular}{|c|c|c|c|c|c|}
\hline \multirow[b]{2}{*}{$\mathrm{IP}_{1}$} & \multicolumn{2}{|c|}{ Input parameters } & \multirow[b]{2}{*}{$\mathrm{IP}_{m}$} & \multirow{2}{*}{$r_{1} \cdot r_{2} \cdot r_{k} \cdot r_{m}$} & \multirow{2}{*}{$\begin{array}{l}\text { Equivalent investigation ratio } \\
\qquad r_{\mathrm{EQ}}\end{array}$} \\
\hline & $\mathrm{IP}_{2}$ & $\mathrm{IP}_{k}$ & & & \\
\hline 1 & 1 & 1 & 1 & $1.00 \cdot 1.00 \cdot 1.00 \cdot 1.00$ & \\
\hline 1 & 1 & 1 & 10 & $1.00 \cdot 1.00 \cdot 1.00 \cdot r_{m, \max }$ & \\
\hline 1 & 1 & 10 & 1 & $1.00 \cdot 1.00 \cdot r_{k, \max } \cdot 1.00$ & \\
\hline \multirow[t]{2}{*}{1} & \multirow[t]{2}{*}{10} & \multirow[t]{2}{*}{1} & \multirow[t]{2}{*}{1} & \multirow{2}{*}{$1.00 \cdot r_{2 \max } \cdot 1.00 \cdot 1.00$} & $r_{1} \cdot r_{2} \cdot r_{k} \cdot r_{m}-1$ \\
\hline & & & & & $r_{1, \text { max }} \cdot r_{2, \max } \cdot r_{k, \text { max }} \cdot r_{m, \text { max }}-1$ \\
\hline 10 & 1 & 1 & 1 & $r_{1, \max } \cdot 1.00 \cdot 1.00 \cdot 1.00$ & \\
\hline 1 & 1 & 10 & 10 & $1.00 \cdot 1.00 \cdot r_{k, \max } \cdot r_{m, \max }$ & \\
\hline$\vdots$ & $\vdots$ & $\vdots$ & $\vdots$ & $\vdots$ & \\
\hline 10 & 10 & 10 & 10 & $r_{1, \text { max }} \cdot r_{2, \text { max }} \cdot r_{k, \text { max }} \cdot r_{m, \text { max }}$ & \\
\hline
\end{tabular}

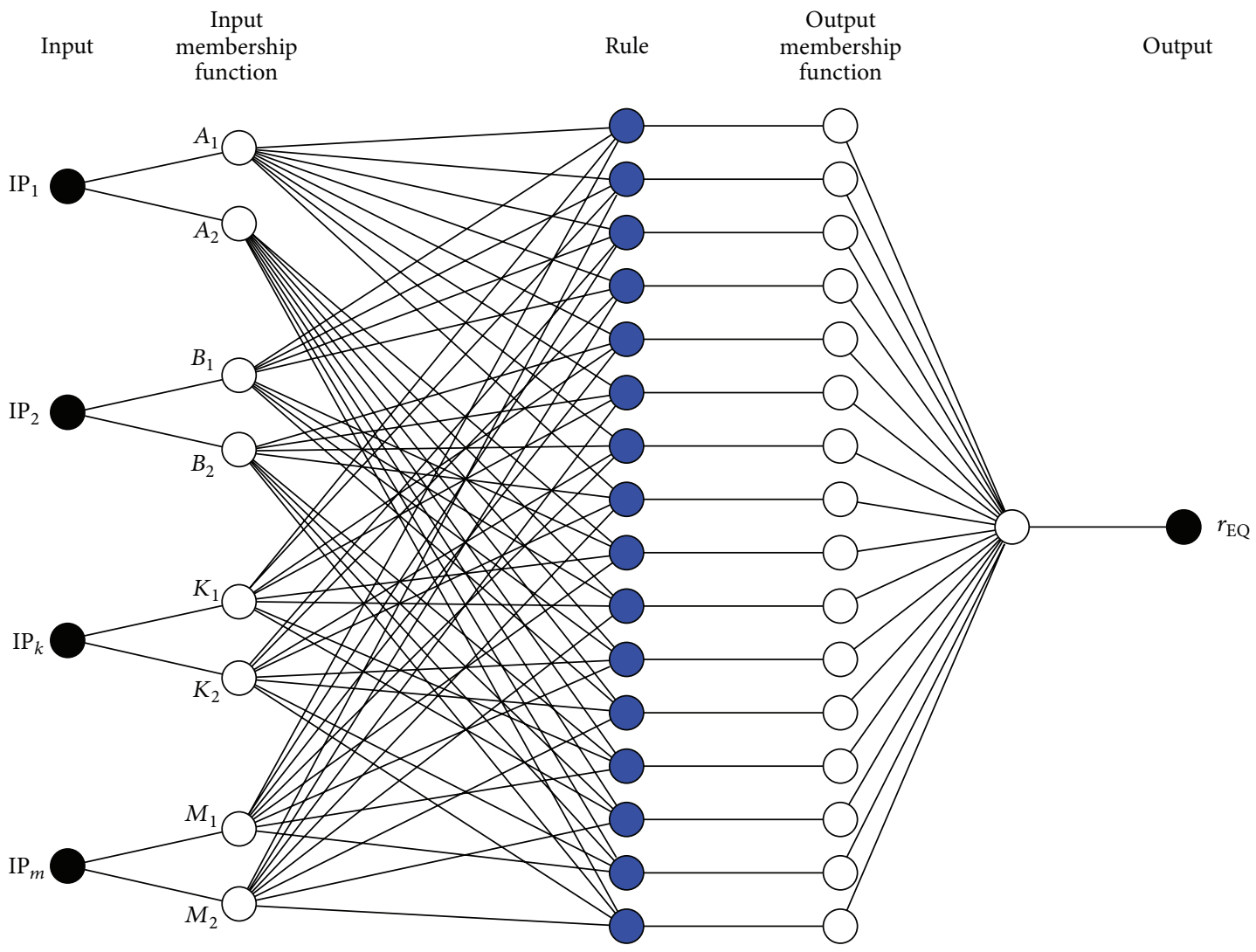

FIGURE 3: ANFIS structure for site investigations.

where $a^{1}, a^{i}, a^{n}$ are consequent parameters and $\mathrm{IP}_{1}, \mathrm{IP}_{2}, \mathrm{IP}_{k}$, and $\mathrm{IP}_{m}$ are input variables. The output of each rule is equal to constant and the final output is the weighted average of each rule's output:

$$
r_{\mathrm{EQ}}=\sum_{i=1}^{n} \overline{w_{i}} \cdot r_{\mathrm{EQ}, i}=\sum_{i=1}^{n} \overline{w_{i}} \cdot\left(a^{i}\right) .
$$

Weights are obtained from Gaussian membership function:

$$
\mu_{A}(x)=\exp \left[-\left(\frac{x-c}{\sqrt{2} \sigma}\right)^{2}\right]
$$

where $c$ is responsible for its center and $\sigma$ is responsible for its width. Parameters $c$ and $\sigma$ are premise parameters. First 
membership grade of a fuzzy set $\left(A_{i}, B_{i}, K_{i}, M_{i}\right)$ is calculated with the following equations:

$$
\begin{aligned}
& \mu_{A_{i}}\left(\mathrm{IP}_{1}\right)=\exp \left[-\left(\frac{\mathrm{IP}_{1}-c_{A_{i}}}{\sqrt{2} \sigma_{A_{i}}}\right)^{2}\right], \\
& \mu_{B_{i}}\left(\mathrm{IP}_{2}\right)=\exp \left[-\left(\frac{\mathrm{IP}_{2}-c_{B_{i}}}{\sqrt{2} \sigma_{B_{i}}}\right)^{2}\right], \\
& \mu_{K_{i}}\left(\mathrm{IP}_{k}\right)=\exp \left[-\left(\frac{\mathrm{IP}_{k}-c_{K_{i}}}{\sqrt{2} \sigma_{K_{i}}}\right)^{2}\right], \\
& \mu_{M_{i}}\left(\mathrm{IP}_{m}\right)=\exp \left[-\left(\frac{\mathrm{IP}}{\sqrt{2}-c_{M_{i}}}\right)^{2}\right],
\end{aligned}
$$

where $\mathrm{IP}_{1}, \mathrm{IP}_{2}, \mathrm{IP}_{k}$, and $\mathrm{IP}_{m}$ are the input to Gaussian membership functions. Next the product of membership function for every rule is calculated:

$$
w_{i}=\mu_{A_{i}}\left(\operatorname{IP}_{1}\right) \cdot \mu_{B_{i}}\left(\mathrm{IP}_{2}\right) \cdot \mu_{K_{i}}\left(\mathrm{IP}_{k}\right) \cdot \mu_{M_{i}}\left(\mathrm{IP}_{m}\right)
$$

where $w_{i}$ represents the fire strength of the rule $i$. Ratio of the $i$ th rule's firing strength to the sum of all rule's firing strengths is defined with

$$
\overline{w_{i}}=\frac{w_{i}}{w_{1}+\cdots+w_{i}+\cdots+w_{n}}, \quad \text { for } i=1,2, \ldots, n
$$

The input data represents a node on the left and right node represents the output data (Figure 3 ). The premise $\left(\sigma_{i}, c_{i}\right)$ and consequent $\left(a_{i}\right)$ parameters of ANFIS-SI model are calculated. By setting the premise and consequent parameters the space of variables is described.

\section{Numerical Example: Project Type "Building"}

A simple example, provided by Bond and Harris [14], considers a site where a new hotel complex is proposed, comprised of a five-story hotel building and associated car parking plus amenity areas. The building area is $80 \mathrm{~m} \times 60 \mathrm{~m}$. The general geology of the area indicates drift deposits comprised of glacial till or sand and gravel overlying Westphalian coal measures. The drift deposits may be up to $15 \mathrm{~m}$ deep and vary laterally. The authors mentioned that the number of investigation points should be in the range of $\left(N_{\min } / N_{\max }\right.$ $=9 / 30$ ) and they proposed 12 as the optimal number of investigation points.

Eurocode 7-2 [1] gives the same recommendations for buildings with grid arrangements. It also recommends 15 to $40 \mathrm{~m}$ spacing in general and $60 \mathrm{~m}$ spacing for large areas.
Bond and Harris [14] use the function "ceiling" and "floor" to determine the number of investigation points

$$
\begin{aligned}
A & =B \cdot L, \\
N_{\text {IP, } \min } & =\text { ceiling }\left(\frac{B}{s_{\max }}+1\right) \cdot \text { ceiling }\left(\frac{L}{s_{\max }}+1\right), \\
N_{\text {IP, } \max } & =\text { floor }\left(\frac{B}{s_{\text {min }}}+1\right) \cdot \text { floor }\left(\frac{L}{s_{\text {min }}}+1\right),
\end{aligned}
$$

where $A$ is the project area of the building, $\mathrm{m}^{2} . L, B$ is the length and width of the building, m. $N_{\text {IP, min }}, N_{\text {IP, max }}$ are the minimum and maximum number of investigation points. $s_{\min }, s_{\max }$ are the minimum and maximum spacing between investigation points, $\mathrm{m}$. Ceiling rounds up to the nearest integer. Floor rounds down to the nearest integer.

Using (23) and (24) gives us the number of investigation points in the form of a step function. For example, the minimum number of investigation points for a building area with a ratio of $B / L=80 / 80 \mathrm{~m}$ is $N_{\text {IP, min }}=4$ and $N_{\text {IP,min }}=9$ for the area with a ratio of $B / L=81 / 81 \mathrm{~m}$. The maximum distance between the investigation points for high-rise and industrial objects is $40 \mathrm{~m}$. But for large areas, the Eurocode 7-2 [1] allows a maximum distance of $60 \mathrm{~m}$.

According to (7), (23), and (24), the suggested minimum $\left(N_{\text {IP,min }}\right)$ and maximum number of investigation points $\left(N_{\text {IP,max }}\right)$ are based on the project area $(A)$ : the lower value $\left(A_{L}\right)$ of the project area with the upper value of the project area $\left(A_{H}\right)$ (see (25)-(26), Figure 4):

$$
\begin{aligned}
& N_{\mathrm{IP}, \min } \\
& = \begin{cases}4 ; & A<A_{L}=1600 \mathrm{~m}^{2}, \\
4+0.0009 \cdot\left(A-1600 \mathrm{~m}^{2}\right) ; & A_{H} \geq A \geq A_{L}=1600 \mathrm{~m}^{2}, \\
16+0.0003 \cdot\left(A-14400 \mathrm{~m}^{2}\right) ; & A \geq A_{H}=14400 \mathrm{~m}^{2},\end{cases} \\
& N_{\mathrm{IP}, \max } \\
& = \begin{cases}9 ; & A<A_{L}=1600 \mathrm{~m}^{2}, \\
9+0.0028 \cdot\left(A-1600 \mathrm{~m}^{2}\right) ; & A_{H} \geq A \geq A_{L}=1600 \mathrm{~m}^{2}, \\
45+0.0009 \cdot\left(A-14400 \mathrm{~m}^{2}\right) ; & A \geq A_{H}=14400 \mathrm{~m}^{2} .\end{cases}
\end{aligned}
$$

4.1. ANFIS Input Factors. For this numerical example, a system of four input factors is presented: layout geometry $\mathrm{LG}=\mathrm{IP}_{1}$, project condition $\mathrm{PC}=\mathrm{IP}_{2}$, geology $\mathrm{GEO}=\mathrm{IP}_{3}$, and similarity $\mathrm{SIM}=\mathrm{IP}_{4}$. An evaluation of these factors (see Table 2) is shown in [16].

Using this system, the equivalent investigation ratio $\left(r_{\mathrm{EQ}}\right)$ is expressed as a function of four project factors:

$$
\begin{aligned}
r_{\mathrm{EQ}} & =\frac{r_{\mathrm{LG}} \cdot r_{\mathrm{PC}} \cdot r_{\mathrm{GEO}} \cdot r_{\mathrm{SIM}}-1}{r_{\mathrm{LG}, \max } \cdot r_{\mathrm{PC}, \max } \cdot r_{\mathrm{GEO}, \max } \cdot r_{\mathrm{SIM}, \max }-1} \\
& =\frac{r_{\mathrm{LG}} \cdot r_{\mathrm{PC}} \cdot r_{\mathrm{GEO}} \cdot r_{\mathrm{SIM}}-1}{r_{\max }-1} .
\end{aligned}
$$

4.2. Decision Criteria. The criteria (Table 3) which were presented in [15] were developed based on past experience 
TABLE 2: Evaluation of Input factors.

\begin{tabular}{lccc}
\hline Number $(k)$ & Parameter $\left(\mathrm{IP}_{k}\right)$ & Criteria & $\begin{array}{c}\text { Max value } \\
r_{k, \max }\end{array}$ \\
\hline 1 & LG & Relationship & 1.10 \\
2 & PC & Length : width (-) & 1.20 \\
3 & GEO & Stress increasing under foundation $(\mathrm{kPa})$ & 1.35 \\
4 & SIM & Similar to existing nearby data (\%). & 1.35 \\
\hline
\end{tabular}

TABLE 3: Agreed-upon criteria, which help in solving complicated multicriteria problems.

\begin{tabular}{|c|c|c|c|c|c|c|c|c|c|c|c|c|}
\hline \multirow{2}{*}{$\begin{array}{l}\text { Number } \\
(k)\end{array}$} & \multirow{2}{*}{ Parameter } & \multirow{2}{*}{ Criteria } & \multicolumn{10}{|c|}{ Rating } \\
\hline & & & 1 & 2 & 3 & 4 & 5 & 6 & 7 & 8 & 9 & 10 \\
\hline 1 & LG & $\begin{array}{c}\text { Relationship } \\
\text { Length : width }(-)\end{array}$ & $1: 1$ & $5: 4$ & $3: 2$ & $7: 4$ & $2: 1$ & $5: 2$ & $3: 1$ & $13: 4$ & $15: 4$ & $4: 1$ \\
\hline 2 & PC & $\begin{array}{l}\text { Stress increasing under } \\
\quad \text { foundation }(\mathrm{kPa})\end{array}$ & 10 & 20 & 30 & 50 & 100 & 150 & 200 & 300 & 500 & $>500$ \\
\hline 3 & GEO & $\begin{array}{c}\text { Subsurface } \\
\text { conditions }(-)\end{array}$ & \multicolumn{3}{|c|}{ High quality and uniform } & \multicolumn{4}{|c|}{ Average } & \multicolumn{3}{|c|}{ Poor quality/erratic } \\
\hline 4 & SIM & $\begin{array}{l}\text { Similar to existing nearby data } \\
(\%) .\end{array}$ & 90 & 80 & 70 & 60 & 50 & 40 & 30 & 20 & 10 & 0 \\
\hline
\end{tabular}

TABLE 4: Main characteristics of the reference site.

\begin{tabular}{|c|c|c|c|c|c|}
\hline Input & Area of project & Layout geometry & Project conditions & Geology & Similarity \\
\hline Data & $\begin{array}{c}L=80 \mathrm{~m} \\
B=60 \mathrm{~m} \\
A=4800 \mathrm{~m}^{2}\end{array}$ & $\begin{array}{c}L / B=80 \mathrm{~m} / 60 \mathrm{~m} \\
L / B \cong 1.3\end{array}$ & five-story hotel & $\begin{array}{l}\text { Four geological layers, } \\
\text { relatively known }\end{array}$ & $\begin{array}{c}\text { The preliminary results show } \\
\text { similarity } \\
\text { (similarity around } 50 \%)\end{array}$ \\
\hline Criteria & $\begin{array}{l}\text { Equations (25) } \\
\text { and (26) }\end{array}$ & \multicolumn{4}{|c|}{ Table 2 and engineering judgment } \\
\hline Assign value & $\begin{array}{c}N_{\text {IP, min }}=7 \\
N_{\text {IP, } \text { max }}=18\end{array}$ & $\mathrm{LG}=2$ & $\mathrm{PC}=4$ & $\mathrm{GEO}=5$ & $\mathrm{SIM}=5$ \\
\hline
\end{tabular}

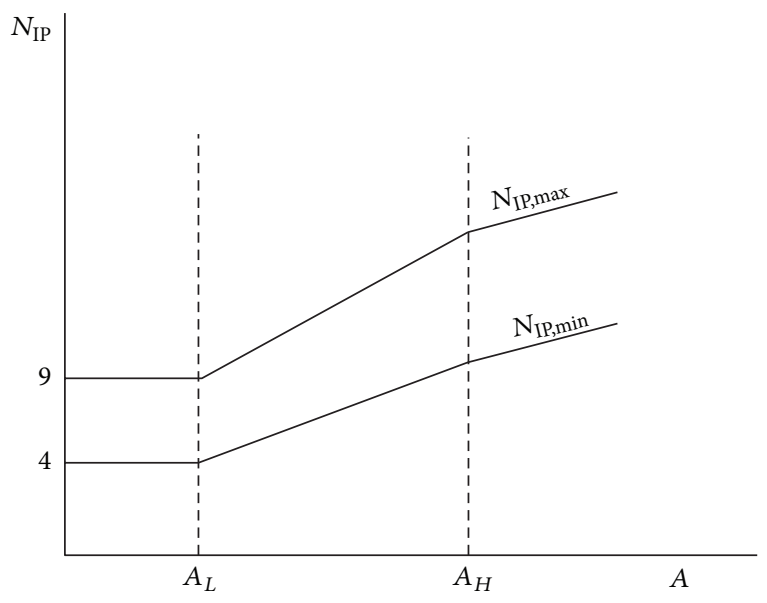

FIGURE 4: Minimum and maximum number of investigation points.

and engineering judgment. The table includes values from 1 to 10 for each parameter of the building site.

Input values for the ANFIS-SI model (see Table 4) were determined based on the criteria shown in Table 3 .
Layout geometry (LG), project conditions (PC), geology (GEO), and similarity (SIM) are all considered input parameters, and the equivalent investigation ratio $r_{\mathrm{EQ}}$ is considered an output parameter (see Table 5). In this model, 16 evaluations were defined for various building site conditions. In the most favorable situation, the values of all parameters are equal to 1 and the minimal number of equivalent investigation ratio $r_{\mathrm{EQ}}$ values is proposed as $r_{\mathrm{EQ}}=0$. Other vertices are obtained by considering the ratios $\left(r_{\mathrm{LG}}, r_{\mathrm{PC}}, r_{\mathrm{GEO}}, r_{\mathrm{SIM}}\right)$ for each parameter.

The calculation procedure of $r_{\mathrm{EQ}}$ is shown in Table 6 .

The fire strength for every rule was calculated. Then the output of each rule was determined using the fire strength combined with the consequent parameters. The final output is the weighted average of each rule's output. The values for numerical examples are given in Table 7.

The value of $r_{\mathrm{EQ}}=0.472$ was obtained from the ANFISSI model and the assigned values (Table 7). Using this value, the optimum number of investigation points $N_{\text {IP,opt }}$ was calculated:

$$
\begin{aligned}
N_{\mathrm{IP}, \text { opt }} & =N_{\mathrm{IP}, \min }+\left(N_{\mathrm{IP}, \max }-N_{\mathrm{IP}, \min }\right) \cdot r_{\mathrm{EQ}} \\
& =7+(18-7) \cdot 0.472=12 .
\end{aligned}
$$


TABle 5: Training datasets.

\begin{tabular}{|c|c|c|c|c|c|}
\hline \multicolumn{4}{|c|}{ Input parameters } & \multirow{2}{*}{$r_{\mathrm{LG}} \cdot r_{\mathrm{PC}} \cdot r_{\mathrm{GEO}} \cdot r_{\mathrm{SIM}}$} & \multirow{2}{*}{$\begin{array}{c}\text { Equivalent investigation ratio } \\
r_{\mathrm{EQ}}\end{array}$} \\
\hline LG & $\mathrm{PC}$ & GEO & SIM & & \\
\hline 1 & 1 & 1 & 1 & 1.00 & 0 \\
\hline 1 & 1 & 1 & 10 & $1.00 \cdot r_{\mathrm{SIM}}=1.35$ & 0.248 \\
\hline 1 & 1 & 10 & 1 & $1.00 \cdot r_{\mathrm{GEO}}=1.35$ & 0.248 \\
\hline 1 & 10 & 1 & 1 & $1.00 \cdot r_{\mathrm{PC}}=1.20$ & 0.142 \\
\hline 10 & 1 & 1 & 1 & $1.00 \cdot r_{\mathrm{LG}}=1.10$ & 0.071 \\
\hline 1 & 1 & 10 & 10 & $1.00 \cdot r_{\mathrm{GEO}} \cdot r_{\mathrm{SIM}}=1.82$ & 0.582 \\
\hline 1 & 10 & 10 & 1 & $1.00 \cdot r_{\mathrm{PC}} \cdot r_{\mathrm{GEO}}=1.62$ & 0.440 \\
\hline 10 & 10 & 1 & 1 & $1.00 \cdot r_{\mathrm{LG}} \cdot r_{\mathrm{PC}}=1.32$ & 0.227 \\
\hline 10 & 1 & 10 & 1 & $1.00 \cdot r_{\mathrm{LG}} \cdot r_{\mathrm{GEO}}=1.49$ & 0.348 \\
\hline 1 & 10 & 1 & 10 & $1.00 \cdot r_{\mathrm{PC}} \cdot r_{\mathrm{SIM}}=1.62$ & 0.440 \\
\hline 10 & 1 & 1 & 10 & $1.00 \cdot r_{\mathrm{LG}} \cdot r_{\mathrm{SIM}}=1.49$ & 0.348 \\
\hline 10 & 10 & 10 & 1 & $1.00 \cdot r_{\mathrm{LG}} \cdot r_{\mathrm{PC}} \cdot r_{\mathrm{GEO}}=1.78$ & 0.553 \\
\hline 1 & 10 & 10 & 10 & $1.00 \cdot r_{\mathrm{PC}} \cdot r_{\mathrm{GEO}} \cdot r_{\mathrm{SIM}}=2.19$ & 0.844 \\
\hline 10 & 10 & 1 & 10 & $1.00 \cdot r_{\mathrm{LG}} \cdot r_{\mathrm{PC}} \cdot r_{\mathrm{SIM}}=1.78$ & 0.553 \\
\hline 10 & 1 & 10 & 10 & $1.00 \cdot r_{\mathrm{LG}} \cdot r_{\mathrm{GEO}} \cdot r_{\mathrm{SIM}}=2.00$ & 0.709 \\
\hline 10 & 10 & 10 & 10 & $r_{\mathrm{LG}} \cdot r_{\mathrm{PC}} \cdot r_{\mathrm{GEO}} \cdot r_{\mathrm{SIM}}=2.41$ & 1 \\
\hline
\end{tabular}

TABLE 6: Premise parameters of Gaussian membership function for the ANFIS-SI model.

\begin{tabular}{lccccc}
\hline Membership function & \multicolumn{2}{c}{ Premise parameters } & $\mu(\mathrm{LG})$ & $\mu(\mathrm{PC})$ & $\mu(\mathrm{GEO})$ \\
$I$ & $\sigma_{i}$ & $c_{i}$ & $\mu(2)$ & $\mu(4)$ & $\mu(5)$ \\
\hline$A_{1}$ & 3.224 & 0.759 & 0.930 & & \\
$A_{2}$ & 4.590 & 9.636 & 0.245 & & \\
$B_{1}$ & 2.897 & 0.618 & & 0.511 & 0.244 \\
$B_{2}$ & 5.112 & 9.339 & & 0.771 \\
$C_{1}$ & 2.652 & 0.512 & & 0.713 \\
$C_{2}$ & 5.246 & 9.256 & & 0.244 \\
$D_{1}$ & 2.652 & 0.512 & & 0.713 \\
$D_{2}$ & 5.246 & 9.256 & & \\
\hline
\end{tabular}

TABLE 7: Consequent parameters for the ANFIS-SI modeland final outputs.

\begin{tabular}{|c|c|c|c|c|}
\hline$i$ & $w_{i}$ & $r_{\mathrm{EQ}, i}=a^{i}$ & $\overline{w_{i}}$ & $\overline{w_{i}} \cdot r_{\mathrm{EQ}, i}$ \\
\hline 1 & $\mu_{A_{1}}(2) \cdot \mu_{B_{1}}(4) \cdot \mu_{C_{1}}(5) \cdot \mu_{D_{1}}(5)=0.028$ & 0.024 & -0.174 & -0.004 \\
\hline 2 & $\mu_{A_{1}}(2) \cdot \mu_{B_{1}}(4) \cdot \mu_{C_{1}}(5) \cdot \mu_{D_{2}}(5)=0.083$ & 0.071 & 0.093 & 0.007 \\
\hline 3 & $\mu_{A_{1}}(2) \cdot \mu_{B_{1}}(4) \cdot \mu_{C_{2}}(5) \cdot \mu_{D_{1}}(5)=0.083$ & 0.071 & 0.093 & 0.007 \\
\hline 4 & $\mu_{A_{1}}(2) \cdot \mu_{B_{1}}(4) \cdot \mu_{C_{2}}(5) \cdot \mu_{D_{2}}(5)=0.241$ & 0.208 & 0.495 & 0.103 \\
\hline 5 & $\mu_{A_{1}}(2) \cdot \mu_{B_{2}}(4) \cdot \mu_{C_{1}}(5) \cdot \mu_{D_{1}}(5)=0.032$ & 0.027 & -0.031 & -0.001 \\
\hline 6 & $\mu_{A_{1}}(2) \cdot \mu_{B_{2}}(4) \cdot \mu_{C_{1}}(5) \cdot \mu_{D_{2}}(5)=0.092$ & 0.079 & 0.309 & 0.024 \\
\hline 7 & $\mu_{A_{1}}(2) \cdot \mu_{B_{2}}(4) \cdot \mu_{C_{2}}(5) \cdot \mu_{D_{1}}(5)=0.092$ & 0.079 & 0.309 & 0.024 \\
\hline 8 & $\mu_{A_{1}}(2) \cdot \mu_{B_{2}}(4) \cdot \mu_{C_{2}}(5) \cdot \mu_{D_{2}}(5)=0.270$ & 0.232 & 0.821 & 0.190 \\
\hline 9 & $\mu_{A_{2}}(2) \cdot \mu_{B_{1}}(4) \cdot \mu_{C_{1}}(5) \cdot \mu_{D_{1}}(5)=0.007$ & 0.006 & -0.114 & -0.001 \\
\hline 10 & $\mu_{A_{2}}(2) \cdot \mu_{B_{1}}(4) \cdot \mu_{C_{1}}(5) \cdot \mu_{D_{2}}(5)=0.022$ & 0.019 & 0.200 & 0.004 \\
\hline 11 & $\mu_{A_{2}}(2) \cdot \mu_{B_{1}}(4) \cdot \mu_{C_{2}}(5) \cdot \mu_{D_{1}}(5)=0.022$ & 0.019 & 0.200 & 0.004 \\
\hline 12 & $\mu_{A_{2}}(2) \cdot \mu_{B_{1}}(4) \cdot \mu_{C_{2}}(5) \cdot \mu_{D_{2}}(5)=0.064$ & 0.055 & 0.637 & 0.035 \\
\hline 13 & $\mu_{A_{2}}(2) \cdot \mu_{B_{2}}(4) \cdot \mu_{C_{1}}(5) \cdot \mu_{D_{1}}(5)=0.008$ & 0.007 & 0.052 & 0.000 \\
\hline 14 & $\mu_{A_{2}}(2) \cdot \mu_{B_{2}}(4) \cdot \mu_{C_{1}}(5) \cdot \mu_{D_{2}}(5)=0.024$ & 0.021 & 0.429 & 0.009 \\
\hline 15 & $\mu_{A_{2}}(2) \cdot \mu_{B_{2}}(4) \cdot \mu_{C_{2}}(5) \cdot \mu_{D_{1}}(5)=0.024$ & 0.021 & 0.429 & 0.009 \\
\hline 16 & $\mu_{A_{2}}(2) \cdot \mu_{B_{2}}(4) \cdot \mu_{C_{2}}(5) \cdot \mu_{D_{2}}(5)=0.071$ & 0.061 & 1.007 & 0.061 \\
\hline
\end{tabular}


TABLE 8: Specification of field and laboratory tests.

\begin{tabular}{|c|c|c|c|c|c|c|c|c|c|c|c|c|}
\hline Comparable experience & Number & Symbol & PSD & Con & $\mathrm{w}$ & $P / d$ & $\mathrm{BDD}$ & $\operatorname{TXL} c_{u}$ & $\operatorname{TXL} \varphi^{\prime}$ & DSS & $E_{\text {oed }}$ & $k$ \\
\hline Extensive & Lower & $N_{T, i, \mathrm{EXL}}$ & 2 & 1 & 1 & 1 & 1 & 1 & 1 & 1 & 1 & 1 \\
\hline Extensive & Higher & $N_{T, i, \mathrm{EXH}}$ & 4 & 3 & 3 & 2 & 2 & 3 & 2 & 2 & 2 & 3 \\
\hline None extensive $=$ max. number & Higher & $N_{T, i, \max }$ & 6 & 5 & 5 & 3 & 4 & 6 & 4 & 4 & 4 & 5 \\
\hline Calculated minimum number & Minimum & $N_{T, i, \min }$ & 2.5 & 1.5 & 1.5 & 1.25 & 1.25 & 1.5 & 1.25 & 1.25 & 1.25 & 1.5 \\
\hline Calculated optimum number & Higher & $N_{T, i, \mathrm{opt}}$ & 4.15 & 3.15 & 3.15 & 2 & 3 & 4 & 3 & 3 & 3 & 3.15 \\
\hline
\end{tabular}

TABLE 9: Specifications of the field and laboratory tests*.

\begin{tabular}{lccccccccccccccc}
\hline$N_{\text {lay }}$ & Depth (m) & Sam & GWM & OW & SPT & PSD & Con & w & $P / d$ & BDD & TXL $c_{u}$ & TXL $\varphi^{\prime}$ & DSS & $E_{\text {oed }}+k$ & $k$ \\
\hline 1 & $0-0.8$ & 12 & - & - & - & - & - & - & - & - & - & - & - & - & - \\
2 & $0.8-7$ & 12 & - & - & 4 & 0 & 3 & 0 & 2 & 3 & 4 & 0 & 3 & 3 & 0 \\
3 & $7-8.3$ & 12 & - & - & 4 & 4 & 0 & 3 & 0 & 0 & 0 & 3 & 0 & 0 & 3 \\
4 & $8.3-8.7$ & 12 & - & - & 4 & 0 & 3 & 0 & 2 & 3 & 4 & 0 & 3 & 3 & 0 \\
5 & $8.7-10.1$ & 12 & - & - & 4 & 4 & 0 & 3 & 0 & 0 & 0 & 3 & 0 & 0 & 3 \\
6 & $<10.1$ & 12 & - & - & 4 & 4 & 0 & 3 & 0 & 0 & 0 & 3 & 0 & 0 & 3 \\
\hline & Sum & 72 & 12 & 12 & 20 & 12 & 6 & 9 & 4 & 6 & 8 & 9 & 6 & 6 & 9 \\
\hline
\end{tabular}

${ }^{*}$ The first stratum should be researched based on the eventual use of material; Sam: sampling, GWM: ground water measurement; OW: observation well; SPT: standard penetration test.

Determining the optimum number of each test $N_{T, i, \text { opt }}$ is similar to determining the number of investigation points (see Table 9). For example, the optimum number of the PSD test $\left(N_{\mathrm{PSD}, l, \text { opt }}\right.$, per stratum) is

$$
\begin{aligned}
N_{\mathrm{PSD}, l, \mathrm{opt}} & =N_{\mathrm{PSD}, l, \min }+\left(N_{\mathrm{PSD}, l, \max }-N_{\mathrm{PSD}, l, \min }\right) \cdot r_{\mathrm{EQ}} \\
& =2.5+(6-2.5) \cdot 0.472=4.15 \approx 4 .
\end{aligned}
$$

The result is the same value suggested in the reference case (Bond and Harris). The minimum depth of investigation points (boreholes) for a five-story concrete building according to Sowers [17] should be

$$
z_{b}(m)=6 \cdot S^{0.7}=6 \cdot 5^{0.7}=18.5 \mathrm{~m}
$$

The applicability of sampling methods, groundwater measurement systems, field tests, and laboratory tests are very important for obtaining the parameters. The specification of field and laboratory tests is presented in Table 8. The calculation considers the minimum number of tests by using the recommendations in the Eurocode 7-2 [1]. Table 9).

The number of single tests was calculated using (2) (see

\section{Conclusion}

This paper deals with determining the optimal quantity of geotechnical investigations required for a construction project. The optimal number of investigative points and the optimal number of each field and laboratory test are defined based on their minimum and maximum number as well as the equivalent investigation ratio. The equivalent investigation ratio describes the optimum number of investigations and is a number between the minimum and maximum values.

The total number of increments between the minimum and maximum amount of investigation points for different building site conditions was determined. To facilitate the decision-making process for a number of investigation points, an Adaptive Network Fuzzy Inference System (ANFIS) was proposed. This system was designed to determine the influence of several entry parameters and to compute the equivalent investigation ratio.

The newly developed ANFIS-SI model is used to characterize any building site. The ANFIS-SI model takes into account project factors such as type of structure, project area, layout geometry, loading, site geology, complexity of geological structure, and the similarity between the preliminary and existing surrounding environment. Each structure requires its own model, depending on its specific characteristics. Project factors are evaluated with a rating from 1 to 10 . The impact of each factor and its correlation to the equivalent investigation ratio is then determined. The ANFIS-SI model, which has integrated recommendations, can be used as a systematic decision support tool for engineers. It is useful in evaluating the number of investigation points, field tests, and laboratory tests required for a building site. The result is written in the general form for each type of structure.

Determining the optimal number of investigative points, field tests, and laboratory tests is presented in the form of a case study. The ANFIS-SI model is easy to use; however its biggest problem is in determining the evaluation ratings of project factors. Site ratings should only be done by experts with experience in the field of construction. The aim of further research should be to improve the decision criteria. This could be done only with cooperation by the experts who 
have a prolonged or intense experience through practice and education in site investigations.

\section{Competing Interests}

The authors declare that they have no competing interests.

\section{References}

[1] Eurocodes, "Geotechnical design-part 2: ground investigation and testing. Annex B, B.3 examples of recommendations for the spacing and depth of investigations," EN 1997-2, Eurocodes, 2007.

[2] B. Look, Handbook of Geotechnical Investigation and Design Tables, Balkema, Taylor \& Francis Group, 2007.

[3] R. E. Hunt, Geotechnical Engineering Investigation Handbook, Taylor \& Francis, New York, NY, USA, 2005.

[4] D. P. Coduto, Foundation Analysis and Design, Prentice Hall, 2nd edition, 2001.

[5] C. Clayton, M. Matthews, and N. Simons, Site Investigation, Department of Civil Engineering, University of Surrey, Guildford, UK, 2005.

[6] L. A. Zadeh, "Fuzzy sets," Information and Computation, vol. 8, pp. 338-353, 1965.

[7] J.-S. R. Jang, "ANFIS: adaptive-network-based fuzzy inference system," IEEE Transactions on Systems, Man and Cybernetics, vol. 23, no. 3, pp. 665-685, 1993.

[8] M. Sugeno, Industrial Applications of Fuzzy Control, Elsevier Science, Amsterdam, The Netherlands, 1985.

[9] D. G. Rumelhart, G. E. Hinton, and R. J. Williams, "Learning representations by back-propagating errors," Nature, vol. 323, pp. 533-536, 1986.

[10] C. M. Tam, T. K. L. Tong, A. W. T. Leung, and G. W. C. Chiu, "Site layout planning using nonstructural fuzzy decision support system," Journal of Construction Engineering and Management, vol. 128, no. 3, pp. 220-231, 2002.

[11] A.-B. Huang, S.-P. Hsu, and H.-R. Kuhn, "Use of fuzzy control in automated soil testing," Geotechnical Testing Journal, vol. 17, no. 3, pp. 356-362, 1994.

[12] I. A. Basheer, L. N. Reddi, and Y. M. Najjar, "Site characterization by neuronets: an application to the landfill siting problem," Ground Water, vol. 34, no. 4, pp. 610-617, 1996.

[13] D. M. Rizzo, T. P. Lillys, and D. E. Dougherty, "Comparisons of site characterization methods using mixed data," ASCE Geotechnical Special Publication, vol. 58, no. 1, pp. 157-179, 1996.

[14] A. Bond and A. Harris, Decoding Eurocode 7, Taylor \& Francis, New York, NY, USA, 2008.

[15] P. Jelušič and B. Žlender, "An adaptive network fuzzy inference system approach for site investigation," Geotechnical Testing Journal, vol. 37, no. 3, 2014.

[16] The MathWorks, MATLAB, Version 7.10.0, The MathWorks, Natick, Mass, USA, 2010.

[17] G. F. Sowers, Introductory Soil Mechanics and Foundations: Geotechnical Engineering, MacMillan, New York, NY, USA, 4th edition, 1979. 

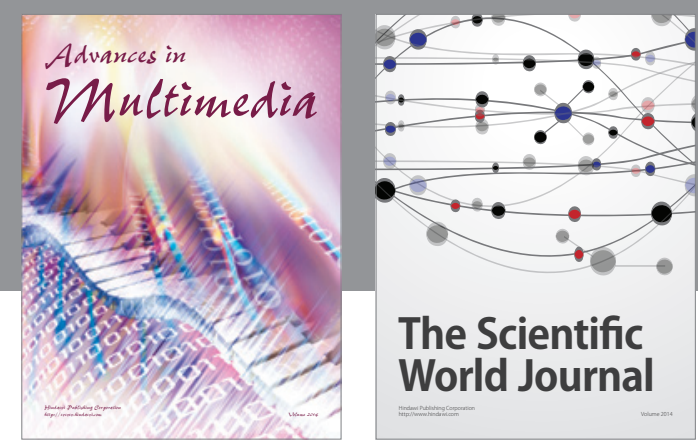

The Scientific World Journal
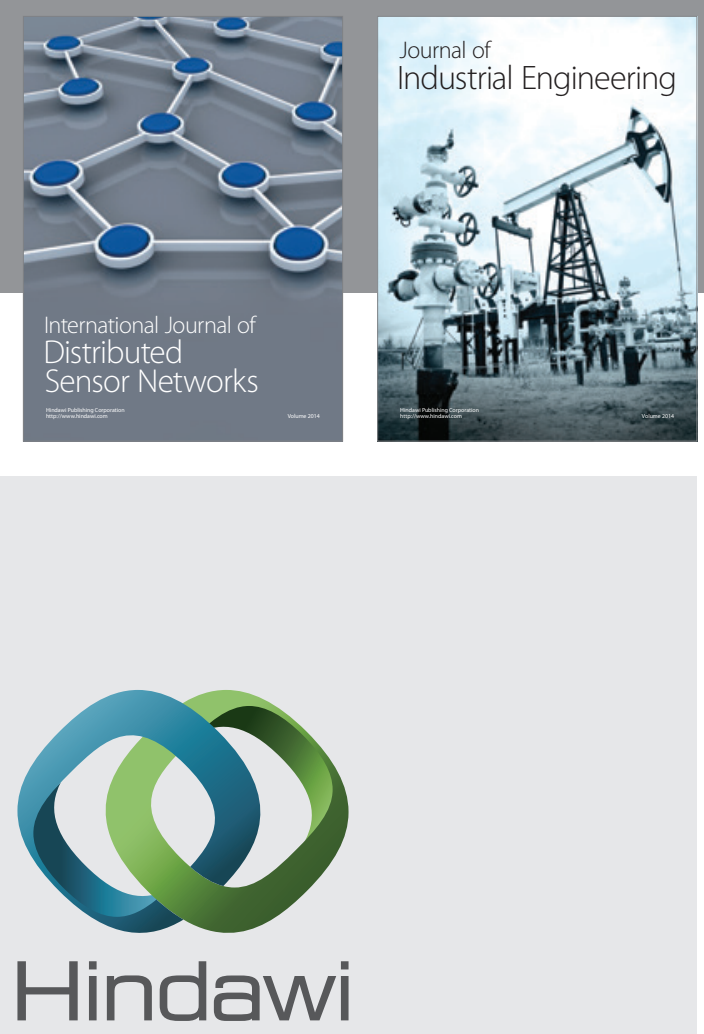

Submit your manuscripts at

http://www.hindawi.com

\section{Computer Networks} and Communications
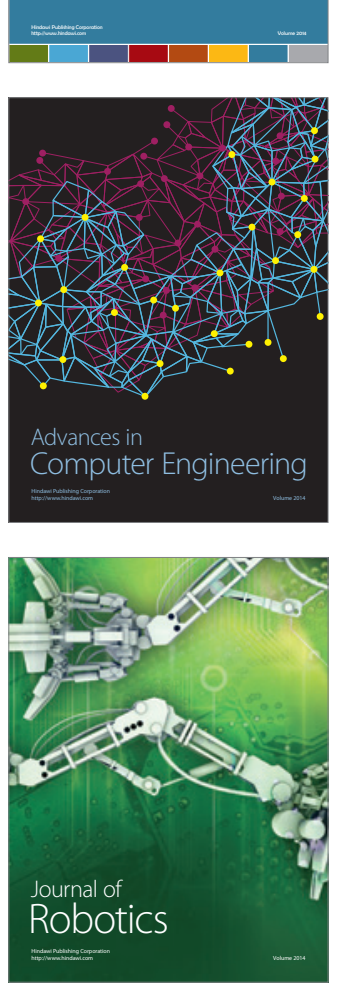
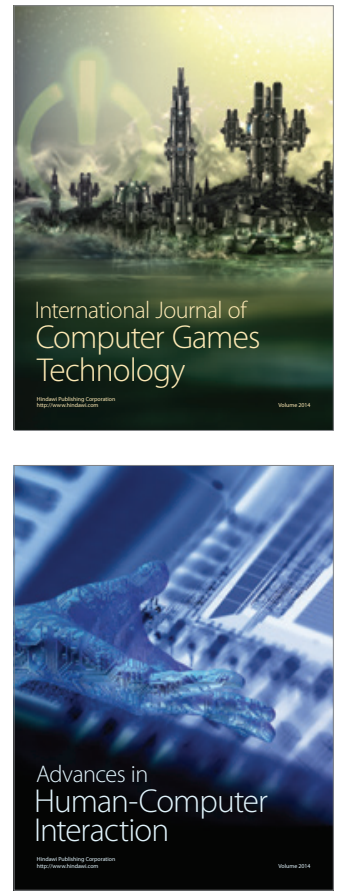
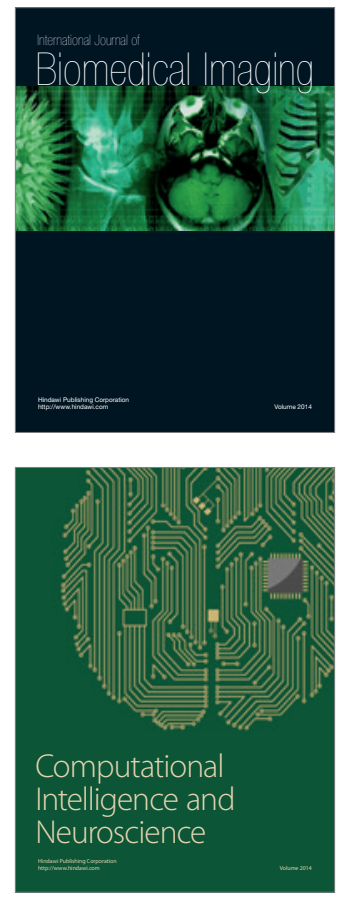
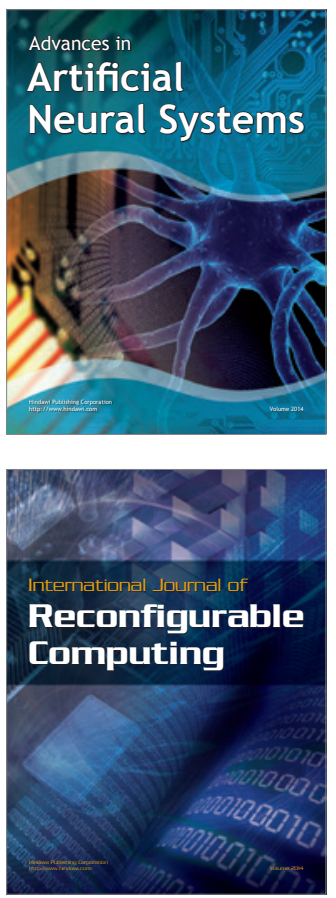
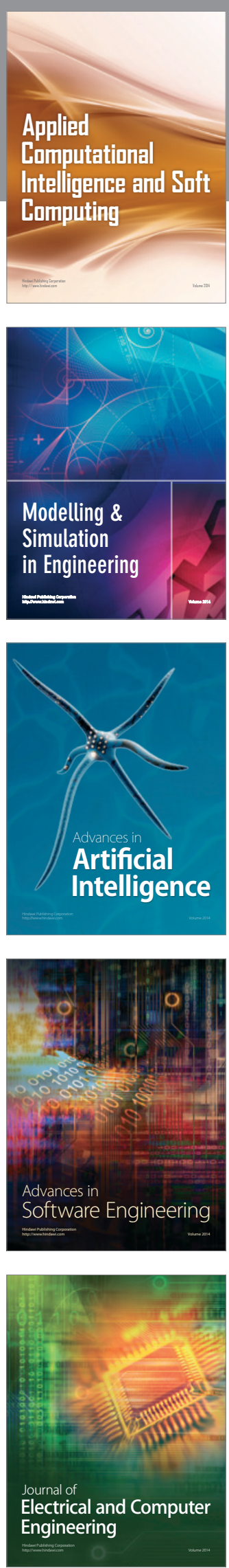